\title{
Escape behavior as determined by schedules of shock and discrete CS presentations'
}

JOSEPH J. FRANCHINA

SOUTHERN METHODIST UNIVERSITY

Rats received escape training, with shock-presentation schedules of $50 \%$ or $100 \%$ and discrete CS-presentation schedules of $0 \%, 50 \%$ or $100 \%$, followed by extinction with the discrete CS alone. Acquisition performance was directly related to shock percentage $(\mathrm{p}<.001)$. No reliable effect of $C S$ was found. Resistance to extinction was inversely related to shock percentage $(\mathrm{p}<.05)$ and, during early extinction, was directly related to CS percentage ( $p<.02$ on extinction Trial Block 1).

In the instrumental shock-escape situation, fear, classically conditioned to the stimuli present at shock application, is presumed to be a partial determinant of escape performance. McAllister \& McAllister (1962) have reported that better classical fear conditioning resulted from pairing shock with the combined stimuli of a discrete CS (light) and static visual and tactile cues of the conditioning box, than from pairing shock with static box cues alone. Thus, if McAllister and McAllister's findings were generalizable to shockescape behavior, one would predict that, all things constant, escape training with the combined stimuli of a discrete CS and static apparatus cues would be superior to training with static cues alone. The first purpose of this experiment was to investigate this hypothesis.

The second purpose of this study was to investigate the effects of intermittent shock schedules on escape behavior, using a different intermittent schedule and more distributed acquisition and extinction sessions than were reported previously (e.g. Franchina, 1966). Method

The apparatus was that described by Franchina (1966). A white start box was separated from a black safe box by a guillotine door and a hurdle. The start box floor could be electrified with 50-volts shock; the only resistance in the shock circuit was $S$. The safe box floor could be depressed.

On top of the start and the safe boxes were compartments which served as lids and contained sources of illumination for the lower boxes. The source for intertrial illumination, $7 \mathrm{ft}-\mathrm{c}$, was a 7-1/2-watt lamp on the left wall of each lid, 16 in, above the floors of the lower boxes. The source for the discrete CS, an increase in start box illumination from 7 to $110 \mathrm{ft}-\mathrm{c}$, was a 40-watt lamp on the right wall of the start box lid, 14 in. above the start box floor. The illumination was reflected from its source by an aluminum foil lining inside each lid. Frosted Plexiglas, 3/16 in. thick, diffused the illumination into the lower boxes.
Ss were 84 naive, female, Holtzman albino rats, 100110 days old at the start of the experiment. Ss were randomly and evenly distributed into a 3 by 2 design for escape training with shock presentation on $50 \%$ or $100 \%$ of the trials and discrete CS (light) presentation on $0 \%, 50 \%$ or $100 \%$ schedules. Static apparatus cues were constantly present in each CS (light) condition.

Each $\mathrm{S}$ received $4 \mathrm{~min}$. of exploration in each side of the apparatus followed, on the next day, by the start of escape training. Forty-eight training trials and, then, 64 non-shock extinction trials were administered at the rate of eight trials per day. A training trial with the discrete CS (light) and shock involved placing Sinto the start box, and after 10 sec., raising the guillotine door, thereby activating a timer (calibrated in $.01 \mathrm{sec}$ ), the light and the shock. If $S$ jumped the hurdle within $40 \mathrm{sec}$. , the safe box floor depressed, turning off light and timer. If $S$ failed to jump the hurdle within $40 \mathrm{sec}$., $S$ was removed from the start box, with light, shock, and timer remaining on, and a latency of $40 \mathrm{sec}$. was recorded. All training and extinction trials followed these procedures except for variations in light or shock schedules.

The schedule of presenting $(+)$ or omitting $(-)$ CS (light) or shock during training for either the 50\% light or the $50 \%$ shock conditions was:,+-+--++- , ,--+++--+ , repeated over blocks of 16 trials. Extinction for all groups was conducted in the presence of the combined stimuli of discrete CS and static box cues. The performance measure was reciprocal of latency of hurdle-jumping.

Results

Figure 1 shows that acquisition performance was directly related to shock percentage; the $100 \%$ CS (light) group performed more poorly than the $0 \%$ and $50 \% \mathrm{CS}$ groups at the end of training. An overall trend analysis of variance of the acquisition data yielded reliable effects for Percentage of Shock, $(F=22.20, \mathrm{df}=1 / 78$, $\mathrm{p}<.001)$ and Trial Blocks, $(\mathrm{F}=95.57, \mathrm{df}=5 / 390$, $\mathrm{p}<.001)$. No reliable effect involving CSpercentage was obtained.

Conceivably, the effects of CS percentage may have been attenuated on shock-escape trials by S's tendency to respond primarily to the shock stimuli, which were more intense than the CS conditions. On non-shock training trials of the $50 \%$ shock schedule, however, performance was presumably determined by the feareliciting properties of the CS conditions alone (fear assumedly was acquired by these same conditions on shock training trials). Thus, the effects of CS presen- 


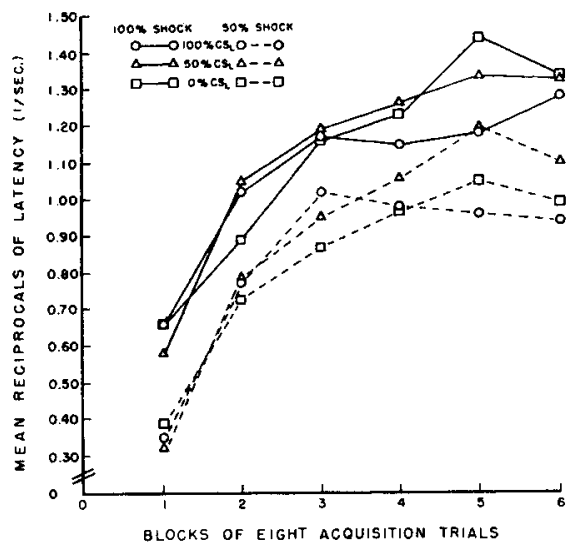

Fig. 1. Mean reciprocals of latency of hurdle-jumping for groups trained with shock schedules of $50 \%$ or $100 \%$, and CS schedules of $0 \%, 50 \%$ or $100 \%$

tations were further evaluated with a trend analysis of the performance of the $0 \%$ and the $100 \%$ CS (light) groups $^{2}$ on the 24 non-shock trials of the $50 \%$ shock schedule. This analysis yielded reliable effects for Trials $(F=13.20$, df $=23 / 598, p<.001)$ and for Trials by CS Percentage $(F=3.12$, df $=23 / 598, p<.001)$. The significant interaction indicated that the $100 \%$ CS group was superior to the $0 \%$ CS group on early non-shock training trials (i.e. Trials $1-5, t(26)=4.00,2.75$, $2.10,<1,2.10, \mathrm{p}<.001,<.02,<.05,>.20,<.05$ respectively) but not on the last non-shock training trial (i.e. Trial 24, $t<1$ )。

Figure 2 shows that extinction performance was directly related to terminal acquisition level for the shock percentage factor. The $50 \%$ and the $100 \% \mathrm{CS}$ groups were generally superior to the $0 \% \mathrm{CSgroup}$. Since the percentage of shock groups differed reliably in acquistion, extinction performance was evaluated

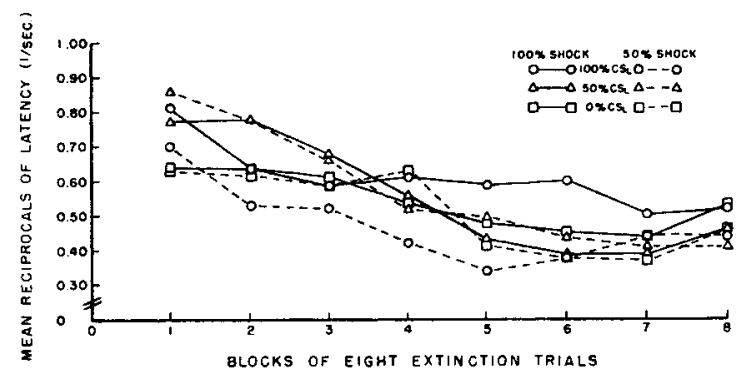

Fig. 2. Mean reciprocals of latency of hurdle-jumping for groups that received shock schedules of $50 \%$ or $100 \%$, and CS schedules of $0 \%, 50 \%$ or $100 \%$ during training. relative to terminal acquisition level for all groups. Relative extinction scores, called percent difference values (Franchina, 1966), were obtained for each $\mathrm{S}$ on each extinction trial block by dividing mean performance on the last trial block of acquisition into the difference in mean performance between the last trial block of acquisition and each trial block of extinction. The percent difference data showed that resistance to extinction was inversely related to shock percentage and directly related to CS percentage. An overall trend analysis of these data yielded reliable effects for Percentage of Shock $(\mathrm{F}=4.12, \mathrm{df}=1 / 78, \mathrm{p}<.05)$, Trial Blocks $(F=29.72, \mathrm{df}=7 / 546, \mathrm{p}<.001)$ and Trial Blocks by CS Percentage $(F=2.53, d f=14 / 546, p<.005)$. Further analyses showed that CS Percentage was significant on extinction Trial Block 1 ( $F=4.25, \mathrm{df}=2 / 78$, $\mathrm{p}<.02)$ but not on Trial Block $8(\mathrm{~F}<1)$. On Trial Block 1 , the $50 \%$ and the $100 \% \mathrm{CS}$ (light) groups were superior to the $0 \%$ group, $t(78)=2.60, p<.02$ in each case, but they did not differ significantly from each other $(t<1)$. Discussion

The effects of shock percentage on acquisition and extinction performance in this study were consistent with the results of Franchina (1966). The present study failed to demonstrate a reliable effect of discrete CS presentations on escape-from-shock training. Analysis of performance on non-shock training trials, however, suggested that this failure may be attributable to the relative intensity of the shock and the CS conditions used. The demonstration of a reliable, facilitative effect of discrete CS presentations on early non-shock training trials suggested tentative support for this explanation, and provided evidence consistent with expectations based on McAllister \& McAllister's (1962) results. On the other hand, these non-shock-trial data must be interpreted cautiously since the facilitative effect of discrete CS presentations dissipated with training.

\section{References}

Franchina, J. J. Effects of shock schedules on the acquisition and extinction of escape behavior. Psychon. Sci., 1966, 4, 277278.

McAllister, W. R., \& McAllister, D. E. Role of the CS and of apparatus cues in the measurement of acquired fear. Psychol. Rep., 1962, 11, 749-756.

\section{Notes}

1. Supported by Grant No. 20-97-152 from the Research Institute of Southern Methodist University.

2. The data of the $50 \%$ CS group were excluded from this analysis since generalized CS conditions were presented on non-shock trials (i.e. static apparat'is cues) instead of the original fear conditioned stimuli (i.e. discrete light plus static cues). 